\title{
The Development of Photocatalyst with Hybrid Material CNT/TiO 2 Thin Films for Dye-Sensitized Solar Cell
}

\author{
Yong Woo Kim ${ }^{1}$ and Sang Hee Park ${ }^{2}$ \\ ${ }^{1}$ Green Energy Convergence Center, Kumoh National Institute of Technology, Daehak-ro 61, Gumi, \\ Gyeongbuk 703-701, Republic of Korea \\ ${ }^{2}$ Department of Mechanical Engineering, Kumoh National Institute of Technology, Gumi 703-701, Republic of Korea
}

Correspondence should be addressed to Sang Hee Park; parksh@kumoh.ac.kr

Received 9 November 2012; Revised 3 June 2013; Accepted 18 June 2013

Academic Editor: Jie-Fang Zhu

Copyright (C) 2013 Y. W. Kim and S. H. Park. This is an open access article distributed under the Creative Commons Attribution License, which permits unrestricted use, distribution, and reproduction in any medium, provided the original work is properly cited.

Dye-sensitized solar cell (DSSC) has big merits of simple manufacturing, low cost, and good applications. However, efficiency of DSSC is quite low compared with other solar cells based on silicon. Ability of electron delivery is important for improving the efficiency; therefore, CNT used as an electrode and transferring electrons and heat significantly easily can be highly expected to contribute to increase conversion efficiency of DSSC. In this paper, CNT was loaded on the photocatalyst of $\mathrm{TiO}_{2}$ thin films in the range from $0 \mathrm{wt} \%$ to $0.01 \mathrm{wt} \%$. CNT was treated with $60 \%$ nitric acid at $120^{\circ} \mathrm{C}$ for $6 \mathrm{hrs}$ and performed on ball milling process for 3 hrs. Hybrid material was made of $\mathrm{TiO}_{2}$ paste and CNT predispersed by mixing. To demonstrate the property of each sample, the analytical techniques including a spectrometer for transmission and surface resistance were used. The sample of higher concentration of CNT has low transmission but low resistance, besides we have researched a proper amount of CNT $0.001 \mathrm{wt} \%$ that can increase $1.5 \%$ conversion efficiency of DSSC.

\section{Introduction}

DSSCs based on nanostructure materials offer very low cost and relatively efficient photovoltaic energy conversion, it has attracted much attention in the last decade. The highest efficiency, to the best of our knowledge, reported on DSSCs was $11 \%$ obtained on nonporous $\mathrm{TiO}_{2}$ by using ruthenium complex dye, containing $\mathrm{I}^{-} / \mathrm{I}_{3}{ }^{-}$redox couple electrolytes and platinum counter electrode [1].

There are several important aspects that need to be considered for a photocatalyst as $\mathrm{TiO}_{2}$ in DSSC. Firstly, it must be able to transfer holes from the sensitizing dye after the dye has injected electrons into the $\mathrm{TiO}_{2}$. Next, it must be able to be deposited within the nanocrystalline layer, and the methods used for the deposition will not dissolve and degrade the monolayer of dye on the $\mathrm{TiO}_{2}$ nanocrystallites [2].

One of major variants of DSSC is that the dye which absorbed the light energy receives the electrons after they are transferred from ground state to excited state. The insertion of electron is done in such a short time as femtoseconds or picoseconds, and the oxidized dyes are recycled in nanoseconds [3].

The recombination speed of the electrons that are disappeared as electrolytes through surface state is so slow as microseconds or milliseconds, resulting that most of the photoelectrons were inserted as the semiconductor does, while the rest that could not be inserted diminishes the solar cells' efficiency as it gets together again with electron holes [4]. If uses CNT, a composite which is useful for electrical and heat transmission can expect speed increase of electron injection speed than recombination speed and increase in efficiency of DSSC through more movement of electrons.

There had been lots of studies focused on carbon nanotube which is widely used in various applications such as Field Emission Display, Fuel Cell, Biosensor, and Atomic Force Microscopy [5]. In addition, nanotube has excellent electrical and mechanical properties and has larger aspect ratio than other conductive fillers which is proper structure for incorporating nanocomposites. With these superior properties, there are lots of trend to develop nanocomposites using nanotubes in and out of Korea [6-8]. 
The Multiwall Carbon nanotube (MWCNT) can function as a basic electrode as it can transfer electricity and heat easily. nanotube functions as an electrode that mutually penetrates through the wide surface of $\mathrm{TiO}_{2}$, as well as helping the electric charges to be extracted efficiently in dye layers. These electrodes are advantageous in solar light spectrum as it has very good transparency in long wavelength.

This paper is aiming at increasing moving speed of electrons that are generated in the dye using $\mathrm{CNT} / \mathrm{TiO}_{2}$ thin films in the $\mathrm{TiO}_{2}$ layers and thus generate current to enhance the efficiency of DSSC. However, though the more it has CNT's contents, the more it decreases the surface resistance, it should provide the optimum environment as it affects current generation through reducing the transmissivity. Also, measure transmissivity and surface resistance of composite film which is CNT acid treated and $\mathrm{TiO}_{2}$; then, apply it to solar cell to evaluate its properties.

\section{Theoretical Background}

2.1. DSSC Principle and Structure. Figure 1 shows the operational principle and structure of DSSC. If visible rays are absorbed by $n$-type nanoparticles $\mathrm{TiO}_{2}$ that dye molecules are chemically absorbed on the surface, the dye molecules generate electron-hole pairs, and the electron were injected into the conduction band of semiconductor's oxides. These electrons that are injected into the semiconductor's oxide electrode generate current through each nanoparticles' interfaces. The holes that are made from dye molecules are deoxidized by receiving electrons, thus causing the DSSCs to begin to work [9].

2.2. CNT Dispersion. In the process of synthesis, CNT aggregation can be observed among each carbon nanotubes' particles. Also, in physical aggregation of micro level, each nanotubes as individual particles will be entangled and wound with each others, whereas chemical aggregation in $\mathrm{nm}$ level can be resulted from surface tension such as Vander Waals forces among molecules. As these kinds of aggregation hinder 3-dimensional network structures forming that can enhance mechanical strength and conductivity properties, it can be said CNT dispersion is a significant process [10].

The dispersion methods are mainly classified into three: chemical, physical, and solvent agent. First, chemical method uses mixed acids such as nitric acid or sulphuric acid to oxidize nanotubes' tip and surface chemically then introduces functional group that contains oxygen such as $-\mathrm{C}=\mathrm{O}$, $-\mathrm{COOH}$, and $-\mathrm{OH}$ [11]. By introducing acid functional group in nanotubes, it increases attraction with water molecules, while nanotubes are electrificated negatively resulting electrostatic interaction. With this, we can get nanotube dispersion solution that shows no sedimentation and is stable. Second, there are methods in physical dispersion. The one is mechanical method that handles ultrasonic waves by mixing acetone and methanol, and the other one is ball milling that reduces length and diameter distribution. Final one is using solvent agents that melt down carbon nanotubes with SDS (sodium dodecyl sulfate) Triton X-100, LDS surfactant.

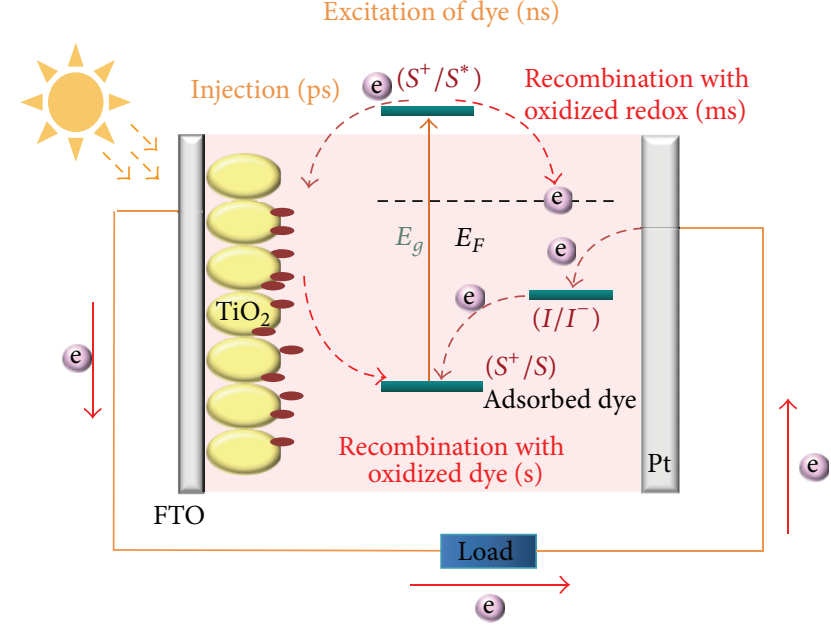

FIGURE 1: A schematic representation of the construction of a DSSC.

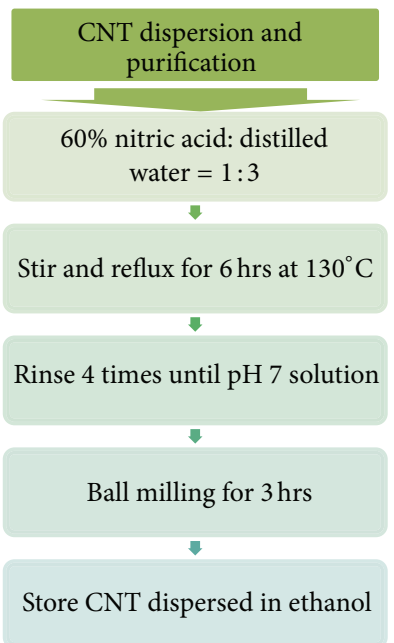

(a)

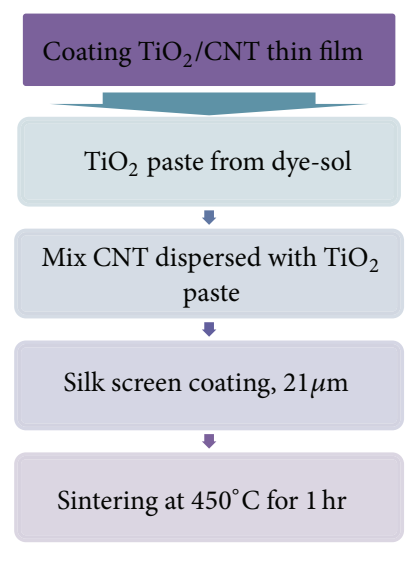

(b)
Figure 2: (a) Process of CNT dispersion and (b) fabricating $\mathrm{TiO}_{2}$ thin film.

\section{Experiment}

3.1. CNT Dispersion. Figure 2(a) shows the dispersion process to protect CNT's aggregation. By mixing $60 \%$ nitric acid and distilled water with a proportion of $1: 3$, carry out reflux work intensely for an hour stirring at $130^{\circ} \mathrm{C}$ with an amount of $1 \mathrm{mg}$ of CNT. After completion of this process, do ultrasonication about 1 hour using lots of distilled water; then, proceed to neutralization process until $\mathrm{pH} 7$ of aqueous solution is reached using $1 \mathrm{~mm}$ diameter of PTFE thin films and vacuum pump. Acidulation with nitric acid makes multiple aggregations be released, and do 3-ball milling for 3 hours to reduce length and diameter effectively.

By filtering, get pure CNTs and follow ultrasonication process in $200 \mathrm{~mL}$ ethanol then store them. If CNT in ethanol does not get together and no visible particles are observed, it can be said the dispersion was successful. If CNT is not 


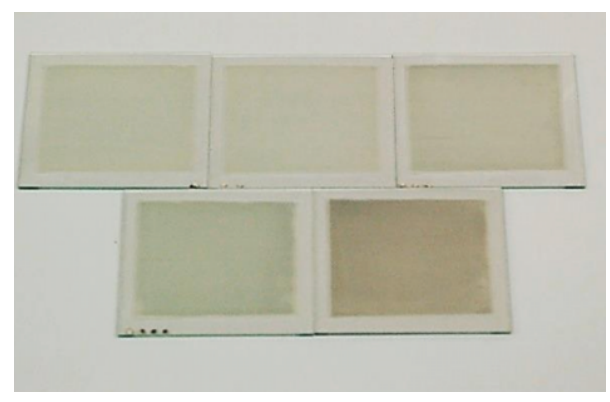

Figure 3: $\mathrm{CNT} / \mathrm{TiO}_{2}$ thin film according to each $\mathrm{CNT}$ wt $\%$.

dispersed, it can cause the powder to be coagulated when it is mixed with $\mathrm{TiO}_{2}$, which may lead to uneven coating on thin films in the process.

3.2. Manufacturing $\mathrm{CNT} / \mathrm{TiO}_{2}$ Thin Film. Figure 2(b) depicts composite thin films making process of CNT and $\mathrm{TiO}_{2}$. To identify DSSC's characteristics according to CNT densities, mix $1 \mathrm{~g}$ of $\mathrm{TiO}_{2}$ (dye-sol) with variable amount of dispersed CNT to make paste of $0.001 \%, 0.002 \%, 0.005 \%$, and $0.010 \%$. To make it have $49 \mathrm{~mm}^{2}$ active area, carry out silk screening process until its thickness reaches $21 \mu \mathrm{m}$. And to ensure even thickness, dry it with constant condition once coating is completed; then, sinter for 30 minutes at $250^{\circ} \mathrm{C}$ for 1 hour at $450^{\circ} \mathrm{C}$.

Figure 3 shows coated plates by CNT concentrations, from which we can see that these plates with high content of CNT have thicker colors.

3.3. Manufacturing DSSC. Figure 4 shows a table about DSSC manufacturing process. $\mathrm{CNT} / \mathrm{TiO}_{2}$ board that is manufactured through sintering process is digested in N719 dying agent at room temperature for 12 hours. Using same process, coat Pt (Dye-sol) on FTO board; then, sinter for 1 hour at $450^{\circ} \mathrm{C}$. With $40 \mu \mathrm{m}$ Surlyn sheet, two boards are sealed, and then inject electrolytes.

\section{Results and Discussion}

4.1. Change of Transmissivity of according to CNT Density. Figure 5 shows transmissivity difference of $\mathrm{CNT} / \mathrm{TiO}_{2}$ thin films by CNT contents. And we measured visible rays' transmissivity using UV/VIS/IR Spectrophotometer (Varian Cary 5000) in a range of $300 \mathrm{~nm} \sim 800 \mathrm{~nm}$. The more it has lots of CNT contents, it can be seen that the transmissivity is decreased steeply, and by adding small amount of CNT, there happens about $20 \%$ difference of thin films' transmissivity that has no CNT in total.

4.2. Surface Resistance Variance according to CNT Densities. Figure 6 shows electrochemical impedance spectra (EIS) using Solar Cell test station (MST-4000A). Impedances were measured under galvanostatic control of the cell. The amplitude of the sinusoidal voltage signal did not exceed $1 \mathrm{~V}$. The current values were acquired by changing conditions

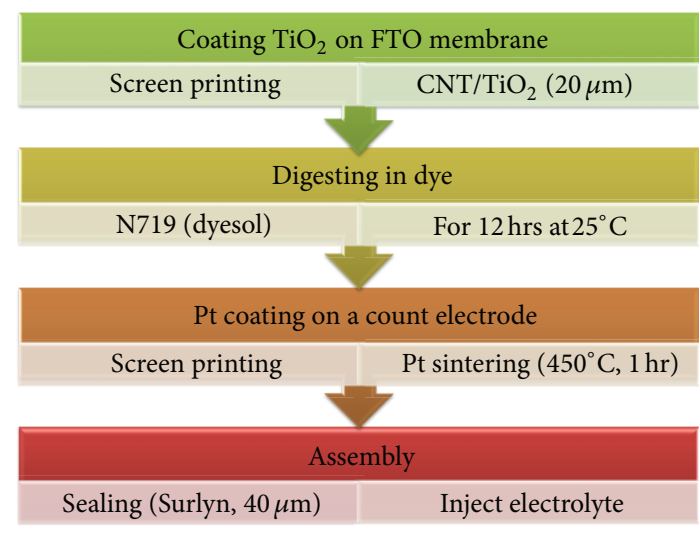

Figure 4: Manufacturing of dye-sensitized solar cell.

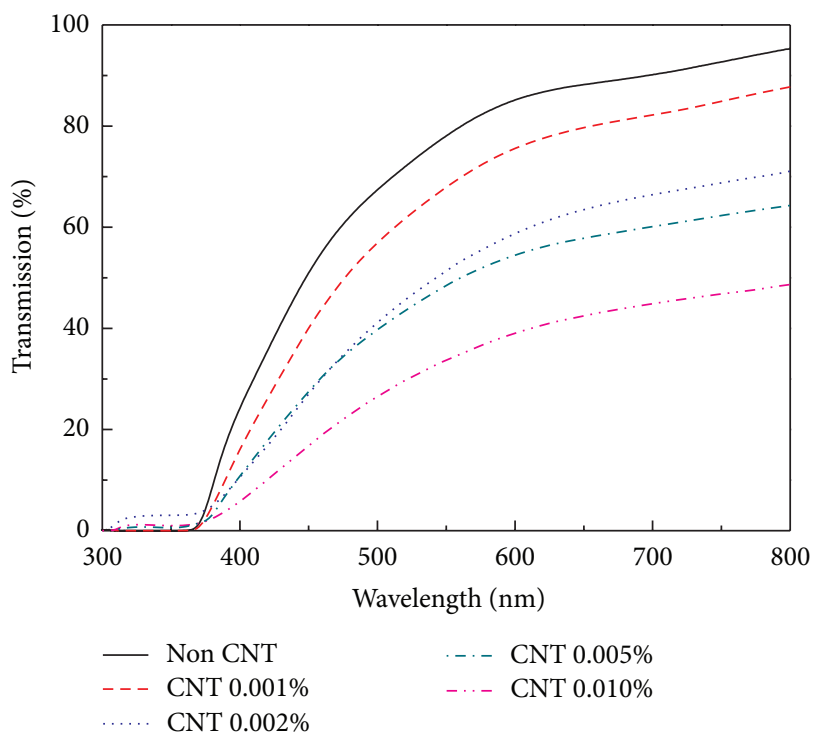

FIgURE 5: Transmission of $\mathrm{CNT} / \mathrm{TiO}_{2}$ thin film.

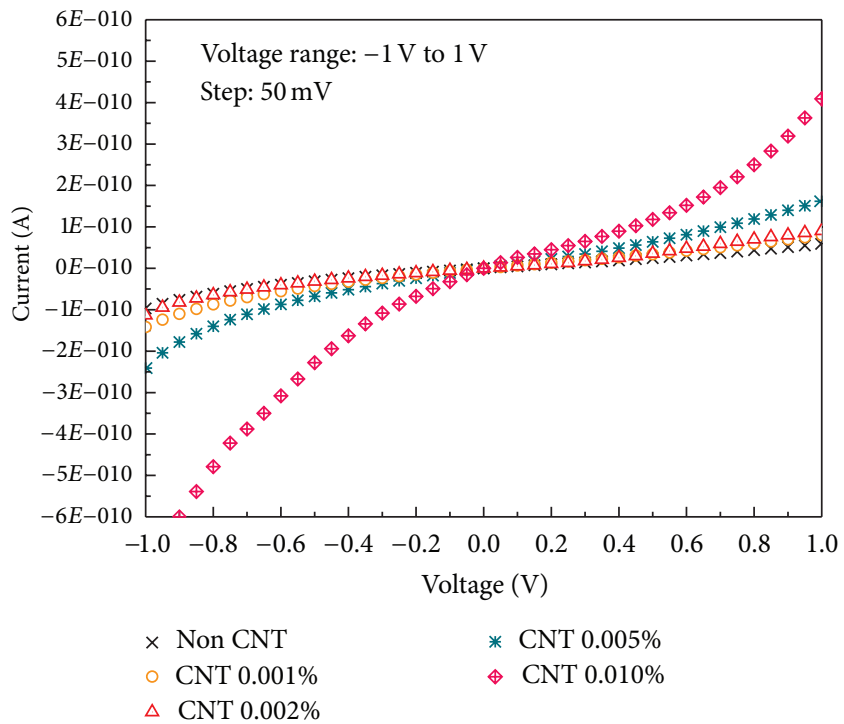

FIGURE 6: $I-V$ curve for surface resistance of $\mathrm{TiO}_{2}$ thin film. 


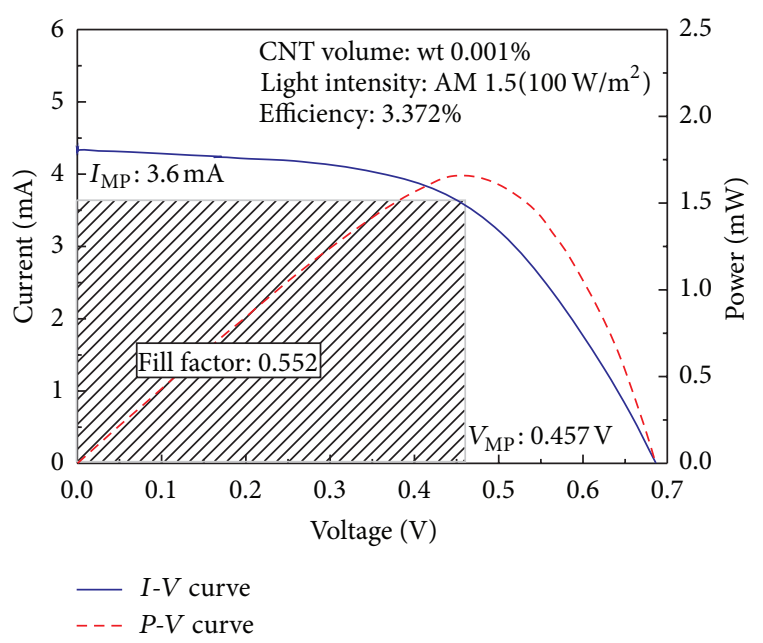

Figure $7: I-V / P-V$ curve of DSSC at $\mathrm{CNT} / \mathrm{TiO}_{2} 0.001 \%$.

from $-1 \mathrm{~V}$ to $1 \mathrm{~V}$ increasing by $50 \mathrm{mV}$ intervals. The resulting impedance was analyzed based on electrical circuit element model. The value of the model elements was determined by fitting the experimental data. $I-V$ curves for the thin films with various CNT content are displayed in Figure 4. As the density of CNT goes high, the slope of $I-V$ curve begins to increase, whereas the resistance value goes down, and the values are almost proportional to the CNT added values. At the intermediated CNT loading of $0.01 \%$, the maximum performance was found over whole current density regimes.

4.3. Efficiency Change according to CNT Densities. Figure 7 shows graphs of current and power according to voltage when the CNT density is $0.001 \%$. The cell's energy transformation efficiency when the CNT is $0.001 \%$ showed the greatest efficiency $(3.372 \%)$ than any other cells. We get voltage $\left(V_{\mathrm{MP}}\right)$ and current $\left(I_{\mathrm{MP}}\right)$ that can generate maximum power output, and by multiplying its values acquire power output, then calculate efficiency using ratios between incident rays energies $\left(P_{\text {in }}\right)$ and generated electric energies $\left(P_{\text {out }}\right)$.

4.4. Change by the Difference of $I_{M P}$ and $V_{M P}$. Figure 8 shows change of $I_{\mathrm{MP}}$ and $V_{\mathrm{MP}}$ according to CNT densities. The $I_{\mathrm{MP}}$ value at $0.001 \%$ cell of CNT was $3.61 \mathrm{~mA}$ which is higher than the one $(2.54 \mathrm{~mA})$ of a cell that did not added CNT. However, as the density is increased more than that, the value decreases as $1.43 \mathrm{~mA}, 1.37 \mathrm{~mA}$, and so forth, and the difference was found to be less than that of when it fell from $0.001 \%$ to $0.002 \%$. This shows that CNT drops transmissivity to cause to reduce electron generation ratio whereas transfers more electrons, and when the CNT density is higher than $0.002 \%$, the larger CNT contents reduce surface resistance, but the generated electrons becomes less as the transmissivity is very low. Furthermore, if this kind of trend assumed to be same as the one of power, we can guess that the current is more influential than that of voltage. And though $V_{\mathrm{MP}}$ values changes between $0.43 \mathrm{~V} \sim 0.49 \mathrm{~V}$ by CNT densities, it cannot be said that it affects more as it may not differ significantly.

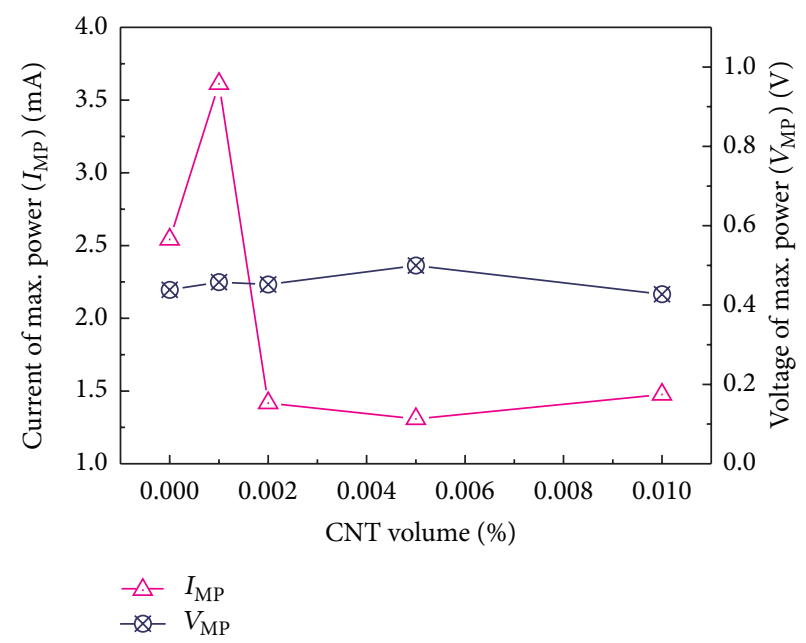

FIGURE 8: $I_{\mathrm{MP}}$ and $V_{\mathrm{MP}}$ of DSSC at each cell with different constant CNT.

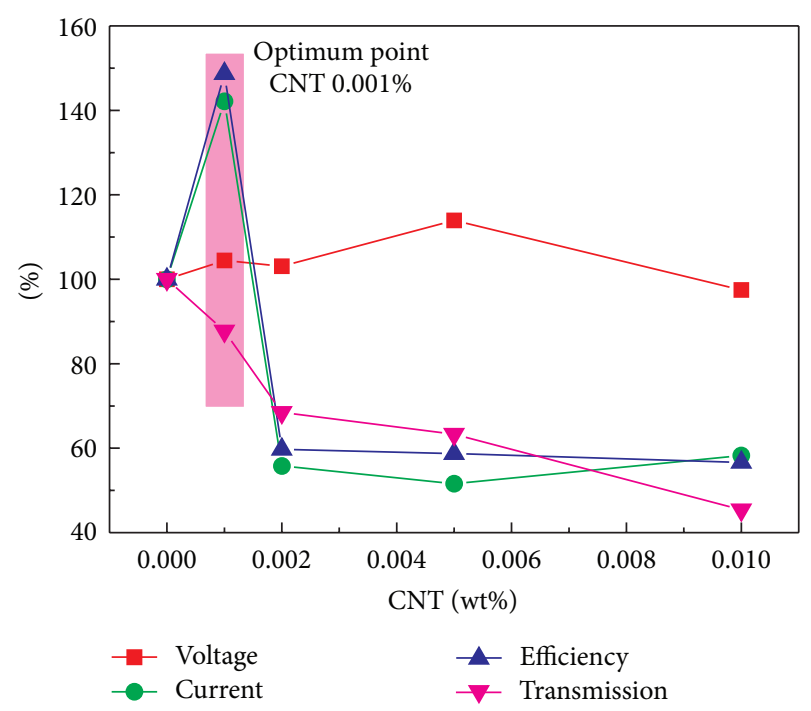

FIGURE 9: Determination of best CNT volume of DSSC.

\section{Conclusion}

Figure 9 shows graphs that compared transmissivity, efficiency, current, and voltage according to CNT densities when the cell that contains no CNT is to be $100 \%$. This study tried to find out how to manufacture $\mathrm{CNT} / \mathrm{TiO}_{2}$ thin films that can enhance the transferring of electrons which were generated in dye as a variant that affects dye sensitized solar cell's efficiency then adopts it to cell to see the efficiency difference between transmissivity and surface resistance. Through this study, we derived conclusions as follows.

(i) $\mathrm{CNT} / \mathrm{TiO}_{2}$ thin film reduces surface resistance, thus enhancing the transfer of electrons.

(ii) As CNT decreases the transmissivity that leads to reduce the generated electric charges, it is found that wt $0.001 \%$ is most proper. 
(iii) The transforming efficiency of cells showed no significant difference among voltages, and seeing the same trend of current, it can be said that the current affects the efficiency.

\section{References}

[1] B. Kilıc, E. Gur, and S. Tuzemen, "Nanoporous $\mathrm{ZnO}$ photoelectrode for dye-sensitized solar cell," Journal of Nanomaterials, vol. 2012, Article ID 474656, 7 pages, 2012.

[2] M. N. Amalina, N. A. Rasheid, and M. Rusop, "The properties of sprayed nanostructured p-type cuI films for dye-sensitized solar cells application," Journal of Nanomaterials, vol. 2012, Article ID 637637, 6 pages, 2012.

[3] J. Teuscher, J. D. Decoppet, A. Punzi, S. M. Zakeeruddin, J. E. Moser, and M. Gratzel, "Photoinduced interfacial electron injection dynamics in dye-sensitized solar cells under photovoltaic operating conditions," The Journal of Physical Chemistry Letters, vol. 3, no. 24, pp. 3786-3790, 2012.

[4] A. Hinsch, J. M. Kroon, R. Kern et al., "Long-term stability of dye-sensitised solar cells," Progress in Photovoltaics, vol. 9, no. 6, pp. 425-438, 2001.

[5] K. Tagami, N. Sasaki, and M. Tsukada, "Simulated nc-AFM images of $\mathrm{Si}(001)$ surface with nanotube tip," Applied Surface Science, vol. 172, no. 3-4, pp. 301-306, 2001.

[6] X. Gong, J. Liu, S. Baskaran, R. D. Voise, and J. S. Young, "Surfactant-assisted processing of carbon nanotube/polymer composites," Chemistry of Materials, vol. 12, no. 4, pp. 10491052, 2000.

[7] H. Koerner, G. Price, N. A. Pearce, M. Alexander, and R. A. Vaia, "Remotely actuated polymer nanocomposites stressrecovery of carbon-nanotube-filled thermoplastic elastomers," Nature Materials, vol. 3, no. 2, pp. 115-120, 2004.

[8] J. K. W. Sandler, J. E. Kirk, I. A. Kinloch, M. S. P. Shaffer, and A. H. Windle, "Ultra-low electrical percolation threshold in carbon-nanotube-epoxy composites," Polymer, vol. 44, no. 19, pp. 5893-5899, 2003.

[9] Y. Liu, J. R. Jennings, S. M. Zakeeruddin, M. Gratzel, and Q. Wang, "Heterogeneous electron transfer from dye-sensitized nanocrystalline $\mathrm{TiO}_{2}$ to $\left[\mathrm{Co}(\mathrm{bpy})_{3}\right]^{3+}$ : insights gained from impedance spectroscopy," Journal of the American Chemical Society, vol. 135, no. 10, pp. 3939-3952, 2013.

[10] N. Grossiord, O. Regev, J. Loos, J. Meuldijk, and C. E. Koning, "Time-dependent study of the exfoliation process of carbon nanotubes in aqueous dispersions by using UV-visible spectroscopy," Analytical Chemistry, vol. 77, no. 16, pp. 5135-5139, 2005.

[11] D. B. Mawhinney, V. Naumenko, A. Kuznetsova, J. T. Yates Jr., J. Liu, and R. E. Smalley, "Surface defect site density on single walled carbon nanotubes by titration," Chemical Physics Letters, vol. 324, no. 1-3, pp. 213-216, 2000. 

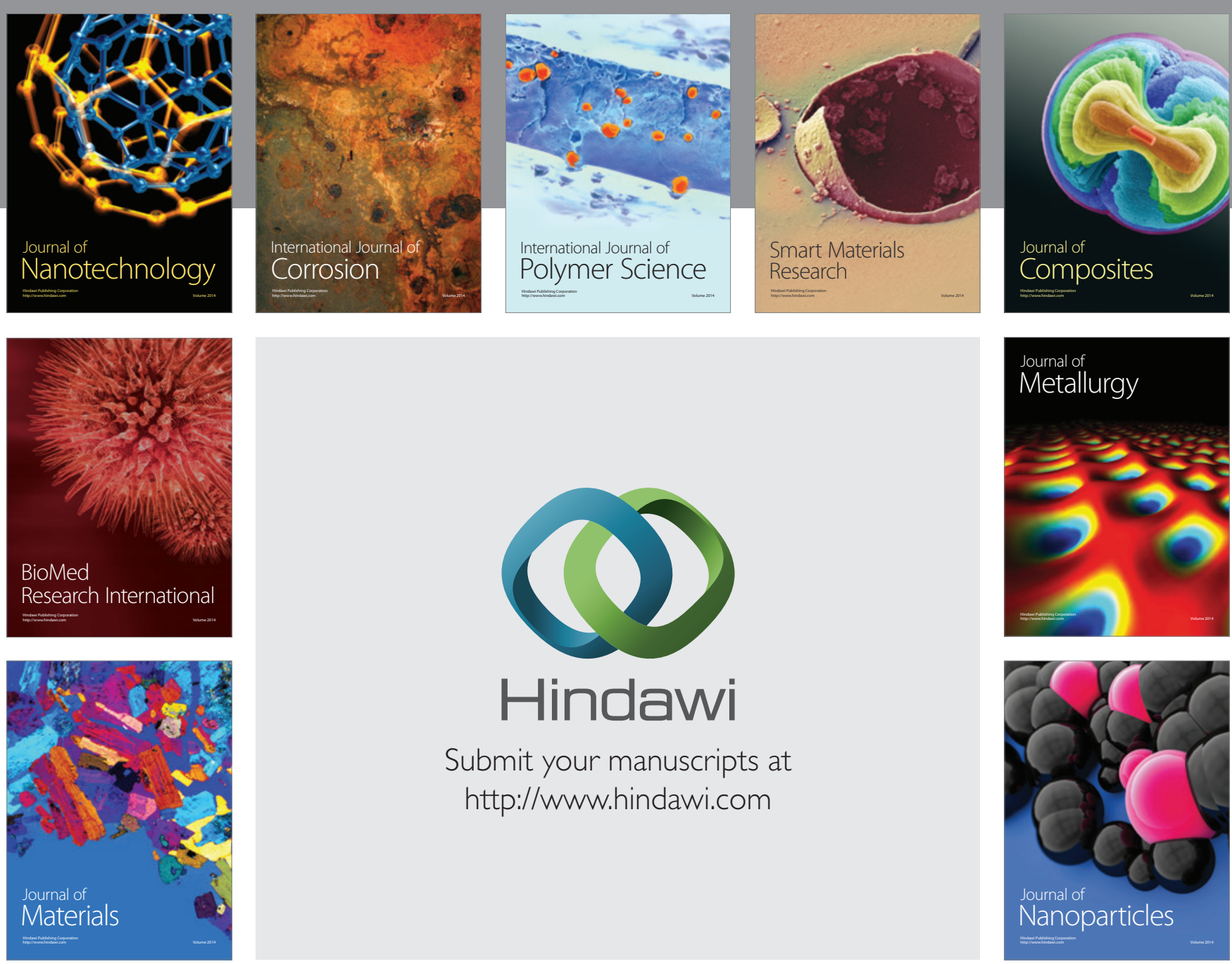

Submit your manuscripts at http://www.hindawi.com
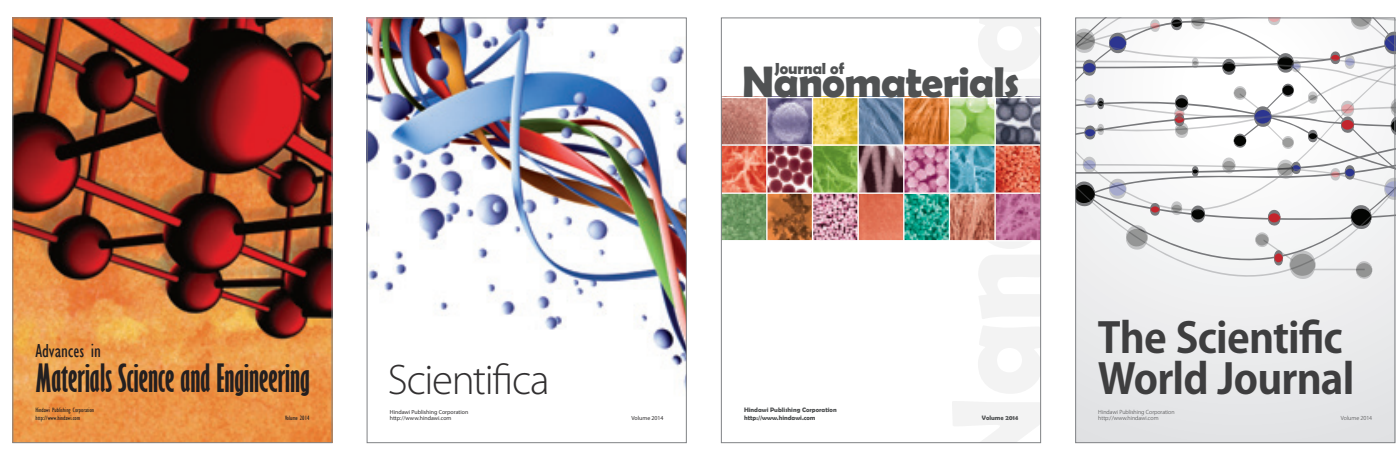

\section{The Scientific World Journal}
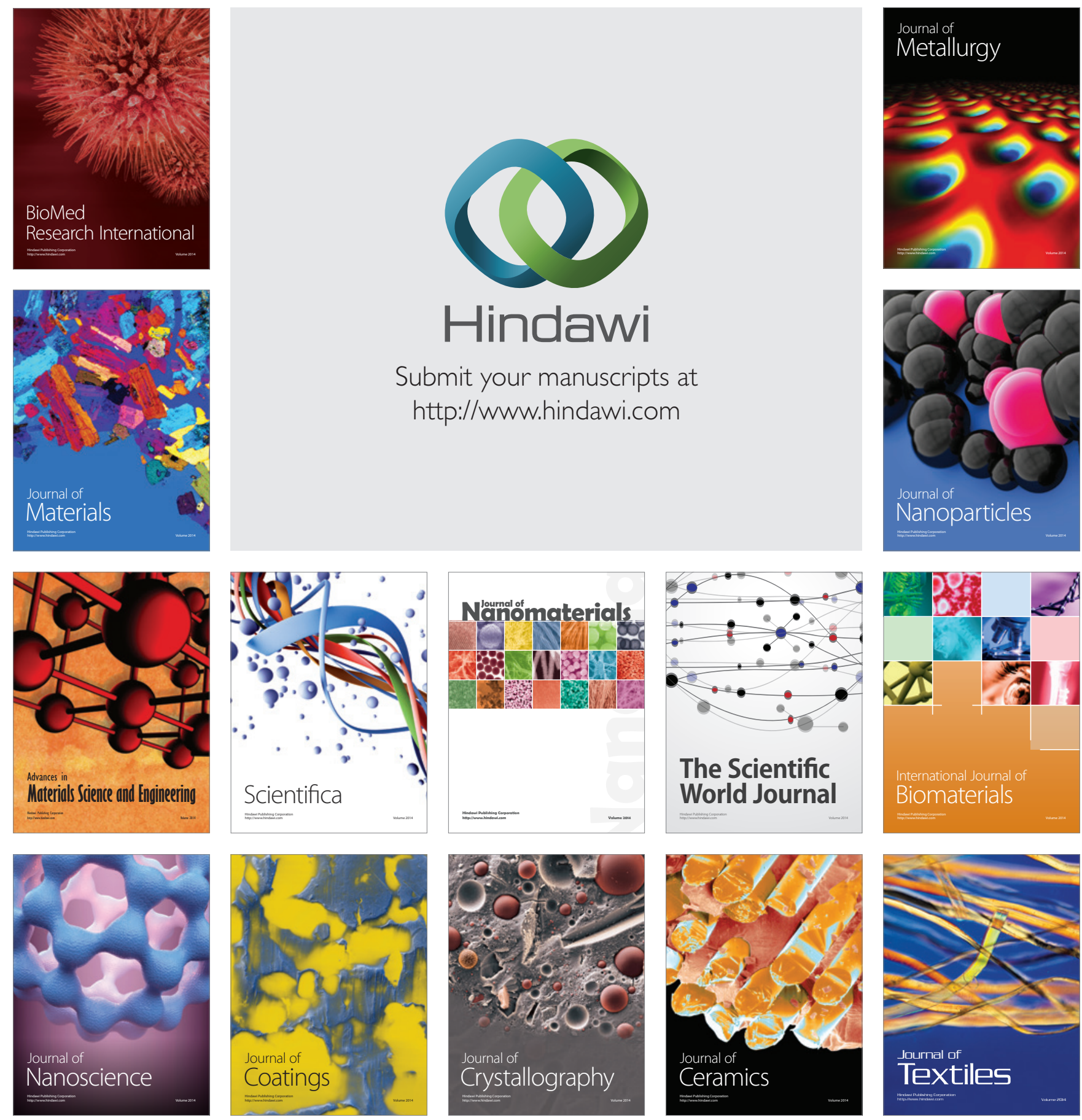